\title{
SITUATION, STRATEGIES AND BMPS TO CONTROL AGRICULTURAL NPS POLLUTION IN THE EUROPEAN UNION ${ }^{\dagger}$
}

\author{
GIORGIO PROVOLO ${ }^{1 *}$, GUIDO SALI ${ }^{1}$, CLAUDIO GANDOLFI ${ }^{1}$, JEONGRYEOL JANG ${ }^{2}$, \\ YOUNGKWEON CHO $^{2}$ AND WILLIAM MAGETTE ${ }^{1}$
}

${ }^{1}$ Department of Agricultural and Environmental Science, Università di Milano, Milano, Italy

${ }^{2}$ Rural Research Institute, Korea Rural Community Corporation, Ansan City, Republic of Korea

\begin{abstract}
Note: please reduce the abstract to not more than 200 words

Although significant improvements in water quality have been achieved in Europe over the last two decades, water quality status is still below desirable levels in many locations. As in many other regions around the world, nonpoint source pollution from agricultural landscapes remains the key cause of water quality problems in many parts of Europe due to nitrogen surplus, and, in some countries, losses of phosphorus. A variety of physical, managerial, financial and political tools exist for addressing nonpoint source pollution from agricultural sources. However, for these to be most effective, they must be applied to areas that are causing the biggest problems. Even then, water resource managers face difficulties in cajoling landowners to adopt the necessary actions, particularly if the effects of such actions to enhance productivity do not exist (or are not apparent). As shown by trends in groundwater quality data, there may be significant delays in observable water quality improvements after action has been taken. These delays in the response times of natural systems will further challenge the willpower of governments at all levels (from local to national) to provide the financial and human resources necessary to combat diffuse pollution. Consequently, there must be continued close cooperation between researchers seeking new control strategies, government agencies that fund such research and finance implementation and landowners who must adopt the measures.
\end{abstract}

\footnotetext{
† Situation, stratégies et BMPS pour lutter contre la pollution agricole NPS dans L'Union Européenne

* Correspondence to: Mr. Giorgio Provolo. Department of Agricultural and Environmental Science, Università di Milano, Via Celoria 2, 20133 Milano,Italy; giorgio.provolo@unimi.it; fax. +39025031 6845; tel. +39025031 6855
} 
KEY WORDS: water quality; nutrient surplus; decision support tools; agri-environmental policy; cross-compliance; Europe.

\section{INTRODUCTION}

Even before publication of Rachael Carson's Silent Spring five decades ago, the potential negative environmental effects resulting from modern agricultural production systems have been well documented by researchers around the world. In the intervening half-century, humans have travelled to and from the moon, yet, environmental activists, farmers themselves and politicians are still battling to minimise the detrimental impacts of agricultural production systems on environmental quality. Why has this problem not yet been solved, as have so many other enormous technical challenges? Is controlling environmental pollution from agriculture actually more difficult than putting humans on the moon and safely bringing them back to Earth? The answer is: 'perhaps'.

The reasons for the occurrence of pollution from agricultural landscapes are myriad, and in many cases do not include irresponsible behaviour by farmers. This is not to say that farmer behaviour can be ignored in combatting diffuse agricultural pollution. Clearly, due to the dominance of agricultural land use in many watersheds, changes in farming practice are required and, thus, so too are changes in farmer behaviour. But, the fundamental challenge for farmers is to know how to behave (i.e., what to do) in these rather unique production systems that are simultaneously affected by the environment and have such a dramatic effect on the environment. The challenge for scientists, environmental managers and politicians is to know how to help farmers do the 'right' things, recognising that farmers have little or no control over many factors that affect diffuse pollution (Table I), operate on very small profit margins, and are virtually unable to pass increased production costs to consumers. 
Table I. Factors influencing anthropogenic water-borne emissions from rural landscapes to water (adapted from Magette et al., 2008)

\begin{tabular}{cc}
\hline Degree of control & Factor \\
\hline No or very little control & Weather \\
Type and history of geologic materials \\
Depth to ground water \\
Soil type \\
Natural drainage density \\
\hline Somewhat controllable & Soil physical characteristics (e.g., bulk density) \\
Drainage (e.g., sub-surface artificial drainage)
\end{tabular}

\section{THE EUROPEAN WATER QUALITY SITUATION}

A composite picture of water quality across the European Union (EU) is provided by the European Environment Agency (EEA), from which much of the following information is derived. In general, water quality in many areas of the EU has been improving or remaining stable over the last two decades (Figure 1).

However, it can also be said that significant improvements in water quality are still necessary. In fact, in a recent review, the European Commission (EC) (2012) concluded that for significant numbers of water resources across the EU, the 'good status' goal would not be reached by the mandated target date of 2015 as contained in the Water Framework Directive (WFD). The contribution of nonpoint agricultural pollution that has been cited as the chief reason why the 2015 WFD target for good status water will not be met in most cases.

The impact of agricultural production on water resources is not surprising considering the extent to which it dominants many catchments. Agricultural land use comprised $47 \%$ of the land area in the so-called EU-25 (25 member states) (EEA, 2010). Utilized agricultural area (UAA) represented approximately $173 \mathrm{M}$ ha in the EU-27 in 2007, of which approximately $25 \%$ was arable land. The EU-27 had a domesticated animal population of over 132 million livestock units (Marquer et al., 2009). Nearly $18 \mathrm{M} \mathrm{kg}$ of active ingredients (expressed as the sum of $\mathrm{N}$, $\mathrm{P}_{2} \mathrm{O}_{5}$ and $\mathrm{K}_{2} \mathrm{O}$ ) in mineral fertilizers were used in 2008 in the EU-27, at an average rate of 108 
$\mathrm{kg} \mathrm{ha}^{-1}$ (Marquer et al., 2009). This nutrient input did not include the nutrient loading from animal manure. The numbers of animals (except poultry) and the consumption of mineral fertilizers have decreased in the EU since 2008, though not uniformly, yet livestock remains one of the greatest agricultural pressures on water quality (European Commission 2013), as localised concentrations of animals are creating large imbalances in $\mathrm{N}$ and $\mathrm{P}$ in some countries, resulting in losses of these elements to the environment.
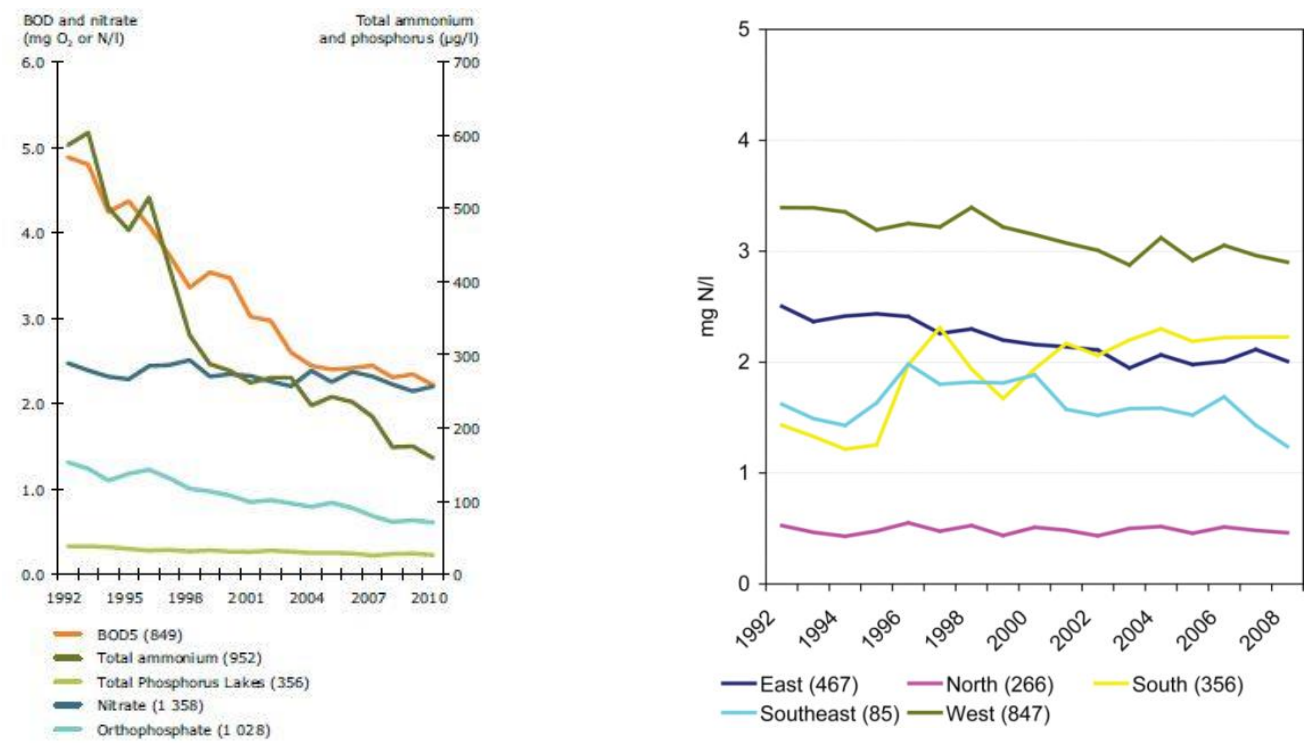

Figure 1. General trends in surface water quality parameters in EU waters, 1992-2012. N.B. Numbers in brackets refer to number of reporting stations analysed. Source: EEA $(2010,2012)$.

The trends in pollutant concentrations shown in Figure 1 are illustrative of the evidence for agriculture's impact on EU water quality. Whereas the trends in parameters such as biochemical oxygen demand (BOD), ammonia-N, and orthophosphate (which are emitted in a relevant way by point sources) have shown rather dramatic reductions in concentrations over time, nitrate-N (which is typically emitted by diffuse agricultural sources) concentrations are declining gradually. The decreases in $\mathrm{BOD}, \mathrm{NH}^{+}-\mathrm{N}$, and $\mathrm{P}$ are thus attributed to the measures introduced by national and European legislation, in particular the Urban Waste Water Treatment Directive (91/271/EEC), which mandates the removal of nutrients from wastewater. The change to use of phosphate-free detergents has also contributed to lower phosphorus concentrations. In contrast, the low rate of reduction in nitrate- $\mathrm{N}$ concentrations across the EU, compared to other parameters, is believed to be the result of continual contributions of this constituent from the agricultural sector's (over)use of organic and chemical fertilisers, as well as the slow release of this constituent from contaminated ground water to surface water.

Nevertheless, with regard to nitrate-N, improvements in ground water quality and surface 
water quality have been noted. For example, in the EU-27 during the period 2008-2011, '14.4\% of groundwater stations exceeded $50 \mathrm{mg}$ nitrate per litre (and $5.9 \%$ were between 40 and $50 \mathrm{mg}$ per litre), but this was a slight improvement compared to the previous reporting period, in which $15 \%$ stations exceeded $50 \mathrm{mg}$ and $6 \%$ were between 40 and $50 \mathrm{mg}$ ' (European Commission 2013). Further, as regards surface waters, 'Based on annual averages of all reported monitoring stations in EU-27, 62.5\% were below $10 \mathrm{mg}$ nitrate per litre, while $2.4 \%$ showed concentrations between 40 and $50 \mathrm{mg}$ per litre and 2.4\% exceeded $50 \mathrm{mg}$ per litre. This is also an improvement compared to the previous reporting period, in which $3 \%$ stations exceeded $50 \mathrm{mg}$ per litre and $2.9 \%$ were between 40 and $50 \mathrm{mg}$ per litre' (European Commission 2013).

Figure 1 (right) also illustrates the marked variation in water quality vis-à-vis nitrate between regions. Rivers in Western Europe have 2-3 mg/l higher concentrations than those in Northern Europe, on average, and the remaining regions have concentrations somewhere in between. Except for the increasing trend in Southern Europe, nitrate concentrations in European rivers are generally decreasing (East, Southeast, West) or fairly stable (North). Rivers draining land with intense agriculture or high population density generally have the highest nitrate concentrations.

Relatively low concentrations of phosphorus in rivers and lakes are found in Northern Europe (Scotland, Norway, Sweden, and Finland), the Alps and the Pyrenees, predominantly reflecting regions of low population density and/or high levels of wastewater collection and treatment. In contrast, relatively high concentrations (greater than $0.1 \mathrm{mg} / \mathrm{l} \mathrm{P}$ ) are found in several regions that have high population densities and intensive agriculture, including: Western Europe (southeast UK, the Netherlands, Belgium), Southern Europe (Italy, central Spain and Portugal), Eastern Europe (Poland, Hungary), and South-Eastern Europe (Bulgaria, Former Yugoslav Republic of Macedonia, Turkey). However, given that phosphorus concentrations greater than 0.1-0.2 mg/l P are generally perceived to be sufficiently high to result in freshwater eutrophication, the observed high values in some regions of Europe are of particular concern.

\section{THE EUROPEAN LEGISLATIVE RESPONSE TO AGRICULTURE-RELATED WATER QUALITY PROBLEMS}

In the EU, four principal policy instruments address environmental pollution from the agricultural sector. Three of these target water pollution directly: the 'Nitrates Directive', the Industrial Emissions Directive (IED), and the Water Framework Directive. The Common Agricultural Policy (CAP) links financial supports that encourage agricultural development to 
environmental (and other) requirements through the principle of 'cross compliance' (European Council 2013).

\section{The 'Nitrates Directive'}

Council Directive 91/676/EEC Concerning the Protection of Waters against Pollution Caused by Nitrates from Agricultural Sources, commonly known as the 'Nitrates Directive', aimed to reduce water pollution caused or induced by nitrate from agricultural sources. The Directive requires Member States to apply agricultural action programme measures throughout their whole territory or within discrete nitrate vulnerable zones (NVZ's), i.e., areas where nonsaline surface waters and groundwater are impaired by nitrate (more than $50 \mathrm{mg} / \mathrm{l} \mathrm{of} \mathrm{NO}_{3}$ ), or might be impaired if adequate measures are not taken. Action programme measures approved by the European Commission must promote best practice in the use and storage of fertiliser and manure; best practice extends to stocking density.

\section{The Industrial Emissions Directive}

The IED originated as the Integrated Pollution Prevention and Control (IPPC) Directive (96/61/EC), which aimed to integrate prevention and control of pollution arising from a specified list of activities, including certain categories of intensive animal production. The IPPC Directive was amended twice (evolving into Directive 2008/1/EC), and as of January 2014 was recast as Directive 2010/75/EU on Industrial Emissions. Like the original IPPC Directive, the IED Directive requires measures to prevent or, where prevention is not practicable, to reduce emissions into the air, water and land from the specified activities. The pollution control measures are so-called 'best available techniques' (BAT) as defined by the European Commission in reference documents (e.g., European Commission, 2003). As new technologies are developed, BAT can change. This directive is a core piece of EU legislation that has been integrated into the Water Framework Directive.

\section{The Water Framework Directive}

The Water Framework Directive, or WFD, (2000/60/EC) is the European Union's (EU) comprehensive legislation for protecting both water quality and water quantity. The WFD articulated ambitious environmental targets, specifically 'to achieve 'good status' for all EU waters, including surface and groundwater, by 2015'. The WFD was unique (for Europe) in its strategy to protect water through a co-ordinated approach in naturally occurring management units (river basins), rather than political boundaries. Importantly, the WFD mandated that river basin management plans (RBMPs) be developed locally (and subsequently approved by the 
European Commission) that comprehensively addressed identified pressures on water quality and quantity in each specific river basin. As such, RBMPs define inter alia agricultural management practices that will minimise impacts on surface and ground water.

\section{The Common Agricultural Policy and 'Cross Compliance'}

In order to better serve the goals of sustainability, including environmental protection, the CAP has continually evolved since 1992. The evolution has consisted of a reform process designed to shift from price support and production to a policy of direct income payments and rural development measures. In the evolution Europe's fundamental agricultural policy has acquired many objectives of environmental policy, becoming itself a tool for achieving environmental goals. The integration of environmental concerns into the Common Agricultural Policy aims to reduce the risk of worsening environmental conditions and improve the sustainability of agro-ecosystems. Two key pillars (fundamental principles) are used to achieve these aims: firstly, the rules for support to agriculture (first pillar) should be compatible with environmental requirements; secondly, measures that foster development of the 'agricultural system' in rural areas (second pillar) should be strongly oriented to the protection of the environment and natural resources.

The implementation of these aims is accomplished through corresponding actions on the two pillars (European Council, 2013):

- $\quad$ strengthening of compliance with environmental laws, by penalizing non-compliance by farmers through a reduction of support payments of the CAP (cross-compliance); and

- allocating payments for rural development measures that promote environmentally sustainable agricultural practices, such as agri-environment schemes (i.e., rural development schemes).

\section{BEST (AGRICULTURAL) MANAGEMENT PRACTICES IN EUROPE}

Increasingly in Europe, as noted in the previous section, agricultural practices that are deemed to be the 'best' at controlling nonpoint source water pollution from agriculture are defined in legislation.

\section{Nonpoint Source Pollution Control via CAP}

Due to its far-reaching role in guiding the direction of European agriculture, the Common Agricultural Policy is arguably the most important legislative tool that affects the majority of 
farmers. Under the CAP, cross-compliance constitutes a set of common rules and standards that farmers have to comply with in order to preserve the environment and the landscape. Common rules and standards are mandatory and are the basis for ensuring that agricultural activity is carried out in a sustainable manner. These rules and regulations constitute the reference level, or 'baseline' and the related compliance costs should be borne by the farmer, according to the 'Polluter Pays Principle'.

However, the common basic rules are not sufficient to achieve the environmental objectives that society expects. Society's environmental demands often go beyond what farmers can be expected to provide through mandatory regulation. In order for farmers to voluntarily implement actions that improve the environment beyond a level resulting from mandatory requirements, it becomes necessary to provide appropriate incentives. These incentives compensate farmers for their use of private resources and factors of production to deliver products and services that are of interest to the whole society. With agri-environment schemes, farmers are paid to voluntarily engage in activities related to the environment ('provider-gets principle').

Today, to ensure that the CAP is compatible with the needs of the market and at the same time is functional to the needs of the environment, it includes four types of measures:

- measures aimed at objectives such as market stability or income support with positive side effects to the environment or that help to maintain environmentally friendly structures (e.g., Less Favoured Areas payments);

- Measures to support income but designed to ensure compliance with the mandatory environmental requirements and the polluter pays principle (e.g., decoupled payments in combination with cross-compliance);

- measures aimed at encouraging the provision of environmental services on a voluntary basis (agri-environment schemes);

- $\quad$ measures to facilitate compliance with the mandatory environmental requirements (e.g., 'meeting standards' measure) or compensate the relative economic disadvantage arising from a region-specific environmental requirements (e.g. Natura 2000 and the Water Framework Directive).

It is difficult to say that any of the four types of measures outlined above are more important than others. However, in terms of encouraging and facilitating environmentallyfriendly farming, perhaps the agri-environmental schemes and the policy of cross-compliance have had the biggest impact.

Agri-environment schemes were first introduced into EU agricultural policy during the 
late 1980s as an option to be applied by Member States. Since 1992, the schemes have become compulsory for Member States in the framework of their rural development plans. Agrienvironmental measures are co-financed by Member States, with the EU share for 2007 - 2013 amounting to almost 20 billion euro or $22 \%$ of spending on rural development. The schemes are designed to incentivize farmers to protect and improve the environment in their farmland by paying them for the provision of environmental services, as defined in terms of specific agricultural practices. Agri-environmental measures can be designed at the national, regional or local level, so that they can be adapted to particular systems of cultivation or farming and specific environmental conditions.

Extensive farming systems, environmentally-friendly farming techniques adapted to the specific needs of a region, and extensive grazing systems are examples of activities encouraged by agri-environment schemes. Other examples of practices covered are environmentally favourable extensification of farming; management of low-intensity pasture systems; integrated farm management and organic agriculture; preservation of landscape and historical features such as hedgerows, ditches and woods; and conservation of high-value habitats and their associated biodiversity.

Importantly, however, agri-environmental schemes remain optional for farmers; in other words, farmers may opt to participate in these schemes or they can ignore them.

Cross-compliance was introduced in 2005 to make the direct payments received under the CAP conditional on compliance by farmers with basic standards relating to the environment, food safety, animal and plant health and animal welfare, as well as the obligation of keeping the land in good condition agricultural and environmental conditions. Cross compliance consists of two categories of obligations:

- $\quad$ Statutory Management Requirements (SMR). These requirements refer to 18 legislative standards in the field of the environment, food safety, animal and plant health and animal welfare;

- Good Agricultural and Environmental Conditions (GAEC). The requirement for maintaining the land in good agricultural and environmental condition refers to a set of standards for soil protection, maintenance of soil organic matter, habitat protection, and management of water resources.

The statutory management requirements refer to the Nitrate Directives and four other directives concerning: conservation and of wild birds (79/409/EEC); protection of groundwater against pollution caused by certain dangerous substances (80/68/EEC); protection of the environment, and in particular of the soil, when sewage sludge is used in agriculture 
(86/278/EEC); conservation of natural habitats and of wild flora and fauna (92/43/EEC). Minimum 'good agricultural and environmental condition' requirements are 'compulsory standards' and should take into account the specific characteristics of the geographic areas concerned, including soil and climatic conditions, existing farming systems, land use, crop rotation, farming practices and farm structures. Minimum requirement can be defined at national or regional level. Member state can also define 'optional standards'.

Thus, whereas the statutory management requirements subject to cross-compliance in the CAP apply uniformly across the EU, those that ensure GAEC can (and do) exhibit considerable variation from one Member State to another, and indeed, within Member States based on local conditions. Certain practices, however, such as protections against soil erosion and the use of buffers to protect water resources, are a common component in the lists of practices defined in most Member States (e.g., Rural Payments Agency 2014).

\section{NPS Pollution Control via WFD}

Not all European farmers choose to participate in CAP. For such farmers, agrienvironmental schemes and environmental measures required under cross-compliance are of little relevance. Nevertheless, all farmers throughout Europe are affected by the WFD through RBMPs. As noted previously, RBMPs are specific to each river basin and the environmental pressures therein. In addition, measures that are included in RBMPs are supposed to be both technically viable and cost-effective. Consequently, there is considerable variability in the measures included in RBMPs across Europe to address water pollution from agriculture. Somma (2013) summarized a review of 10 wide ranging agricultural measures found in many RBMPs (Table II). The list of management practices in Table II is far from exhaustive. For example, Price et al. (2011) describe over 80 individual NPS pollution mitigation methods for use on farms in the United Kingdom.

As noted previously, the WFD incorporated by reference both the Nitrates Directive and the Industrial Emissions Directive. Under the Nitrates Directive, Member States must develop voluntary codes of good agricultural practice that are applicable in nitrate vulnerable zones. In the least, such plans must promote best practice in the use and storage of fertiliser and manure through 4 key measures:

1. limiting inorganic $\mathrm{N}$ fertiliser application to crop requirements;

2. $\quad$ limiting organic manure applications;

3. placing seasonal restrictions on the application of slurry, manures and other organic sources of nitrogen (e.g., wastewater biosolids) on sandy and shallow soils; and

4. requiring maintenance of farm records that document cropping, livestock numbers and 
fertiliser management.

Table II. Typical agricultural BMPs implemented under the WFD (Somma 2013).

\begin{tabular}{|c|c|}
\hline Buffer strips & Plant cover in winter \\
\hline Establishment and preservation of wetlands & Catch crops \\
\hline Reduce water abstraction & Applicationtechniques of manure \\
\hline Reduce fertilisation & Capacity of manurestorage \\
\hline $\begin{array}{l}\text { Avoiding spreading fertiliser and manure at } \\
\text { high risk times and places }\end{array}$ & Erosion-minimisingcultivationsystem \\
\hline
\end{tabular}

The Nitrates Directive also limits the amount of nitrogen from livestock that can be applied to the soil to a maximum of $170 \mathrm{~kg}$ per ha per year in vulnerable zones. Unless a derogation of this limit is granted by the European Commission, it is a non-negotiable requirement.

Management practices, i.e., BAT, required under the Industrial Emissions Directive mirror much of the requirements on nutrient use as specified in the Nitrates Directive, but are even more prescriptive as BAT applies to all nutrients and other possible pollutants arising from the rearing of pigs and poultry (e.g., medicines, pesticides, etc.) and addresses energy conservation, noise pollution, atmospheric emissions and animal welfare (European Commission 2003). In terms of $\mathrm{N}$ and $\mathrm{P}, \mathrm{BAT}$ encompasses the range of practices from animal nutrition to how the animal excreta are collected, stored and utilised. Pig and poultry producers that are large enough to be subjected to the IED have no choice as to whether to comply with the BAT requirements.

\section{EFFECTIVENESS OF AGRICULTURAL BMPs}

Due to the complex interaction of the many variables that affect nonpoint source pollution from agricultural sources, assessing the impact of agricultural best management practices presents immense challenges. Not the least of these challenges is identifying where precisely in a landscape pollutants emanate, or indeed, where are the most pressing problems. These things can only be determined with certainty through direct measurements, i.e., environmental monitoring. Although ambient monitoring of water quality is a requirement of the WFD, the intensity of monitoring stations is generally not high enough to attribute observed changes in water quality to specific changes in management practices on the landscape. Thus, intensive 
monitoring of small catchments having 'representative' characteristics is a superior, though more costly, approach to ambient monitoring for assessing the effectiveness of agricultural management practices.

Although BMP effectiveness studies do exist (e.g., Mellander et al., 2012), they are not yet widespread enough, nor have they been conducted for sufficient durations of time to enable absolute statements about how well particular BMPs control NPS pollutants in particular settings. The European Commission (2013) noted 'As regards the effectiveness of the action programmes in preventing and reducing water pollution by nitrates, very little information has been reported by Member States, which gives cause for concern.' As a substitute, mathematical models have been used with relative success to project the likely water quality improvements arising from changes in agricultural management (e.g., Kersebaum et al., 2003; Collins and Anthony 2008; Sigram et al., 2008; Jung et al., 2010; Daggupati et al., 2011; Liu et al., 2013).

Mathematical models also facilitate the implementation of BMPs in areas within watersheds where they are likely to have the greatest impacts. This improves cost-effectiveness of control programmes, though Giri et al. (2012) warned that '. . . emphasis should be placed on selection of the proper targeting method and BMP to meet the needs and goals of a BMP implementation project because different targeting methods produce varying results'.

Unfortunately, legislative attempts to control NPS agricultural pollution, such as the Nitrates Directive, the Water Framework Directive, and the Common Agricultural Policy continue to foster a so-called 'one-size-fits-all' strategy, in which a uniform approach is taken to address a particular pollution problem regardless of site-specific conditions. Such a strategy is grossly inefficient, albeit politically palatable (e.g., Sharpley et al., 1993; Sharpley 1995; Li and Meh 2004; Doody et al., 2012) and relatively easy to administer.

\section{SUMMARY AND CONCLUSIONS}

Strong, EU-wide legislation gives a legal basis for controlling nonpoint agricultural pollution through the Common Agricultural Policy, the Water Framework Directive, the Nitrates Directive and the Industrial Emissions Directive. As yet, however, water quality remains unsatisfactory in many areas primarily due to this source of pollution, leading to the following conclusions.

The general failure to control diffuse agricultural pollution must be due to inadequate control practices, inadequate implementation of control practices, or implementation of practices in the wrong places. 
To the extent that BMPs are inadequately implemented, water resource managers face difficulties in cajoling landowners to adopt the necessary actions, particularly if the productivity effects of such actions do not exist (or are not apparent) and / or the adoption costs suppress farm profitability.

Therefore, there must be continued close cooperation between researchers seeking new control strategies, government agencies that fund such research and finance implementation, and landowners who must adopt the measures.

\section{REFERENCES}

Collins A, Anthony S. 2008. Assessing the likelihood of catchments across England and Wales meeting 'good ecological status' due to sediment contributions from agricultural sources, Environmental Science and Policy 11: 163-170.

Daggupati P, Douglas-Mankin K, Sheshukov A, Barnes P, Devlin D. 2011. Field-level targeting using SWAT: mapping outputs from HRUs to fields and assessing limitations of GIS input data, Transactions of the American Society of Agricultural and Biological Engineers 54 (2): 501-514.

Doody D, Archbold M, Foy R, Flynn R. 2012. Approaches to the implementation of the Water Framework Directive: Targeting mitigation measures at critical source areas of diffuse phosphorus in Irish catchments, Journal of Environmental Management 93: 225-234.

European Commission. 2003. Reference Document on Best Available Techniques for Intensive Rearing of Poultry and Pigs. Joint Research Centre Institute for Prospective Technological Studies, Seville. Available at http://eippcb.jrc.ec.europa.eu

European Commission. 2012. Report from the Commission to the European Parliament and the Council on the Implementation of the Water Framework Directive (2000/60/EC) River Basin Management Plans, COM(2012) 670 final. European Commission, Brussels, Belgium.

European Commission. 2013. Report from the Commission to the European Parliament and the Council on, the implementation of Council Directive 91/676/EEC concerning the protection of waters against pollution caused by nitrates from agricultural sources based on Member State reports for the period 2008-2011, COM(2013) 683 final. European Commission, Brussels.

European Council. 2013. Regulation (Eu) No 1306/2013 of the European Parliament and of the Council of 17 December 2013 on the Financing, Management and Monitoring of the 
Common Agricultural Policy and Repealing Council Regulations (EEC) No 352/78, (EC) No 165/94, (EC) No 2799/98, (EC) No 814/2000, (EC) No 1290/2005 and (EC) No 485/2008. Brussels: Official Journal L 347, 20/12/2013, p. 0549-0607.

European Environment Agency (EEA). 2010. The European Environment State and Outlook 2010: Freshwater Quality. Copenhagen, Denmark.

European Environment Agency (EEA). 2012. European Waters - Assessment of Status and Pressures. Copenhagen, Denmark.

Giri S, Nejadhashemi A, Woznicki S. 2012. Evaluation of targeting methods for implementation of best management practices in the Saginaw River Watershed. Journal of Environmental Management 103: 24-40.

Jung J, Jang J, Kwon H, Jung J, Yoon K. 2010. Simulation of Streamflow Using SWAT Auto Calibration Tool Over the Saemangeum Watershed, In: Proceedings, 2010 International SWAT Conference (Nam-Won Kim and Raghavan Srinivasan, eds.), pp. 392-397. Available at http://swat.tamu.edu/media/33774/swat2010-proceedings.pdf (Accessed December 2013).

Kersebaum K, Steidl J, Bauer O, Piorr H. 2003. Modelling scenarios to assess the effects of different agricultural management and land use options to reduce diffuse nitrogen pollution into the river Elbe, Physics and Chemistry of the Earth 28, 537-545.

Li K-D, Meh M-C. 2004. Nonpoint Source Pollution Potential Index: A Case Study of the Feitsui Reservoir Watershed, Taiwan, Journal of the Chinese Institute of Engineers 27(2): 253-259.

Liu R, Zhang P, Wang X, Chen Y, Shen Z. 2013. Assessment of effects of best management practices on agricultural non-point source pollution in Xiangxi River watershed. Agricultural Water Management 117: 9-18.

Magette WL, Hallissey R, Hughes K, Cosgrove E. 2008. Eutrophication from Agricultural Sources: Field- and Catchment-scale Risk Assessment. Environmental Protection Agency, Johnstown Castle Estate, Wexford, Ireland.

Marquer P, Pop J, Olsen O, Cardoso F, Ollier C, Ataide Dias R, Baudouin L. 2009. Agricultural statistics 2009 edition. Eurostat, Copenhagen, Denmark (available at http://ec.europa.eu/eurostat).

Mellander P, Melland A, Jordan P, Wall D, Murphy P, Shortle G. 2012. Quantifying nutrient transfer pathways in agricultural catchments using high temporal resolution data, Environmental Science and Policy 24: 44-57.

Price J, Harris D, Taylor M, Williams J, Anthony S, Duethmann D, Gooday R, Lord E, Chambers B, Chadwick D, Misselbrook T. 2011. An Inventory of Mitigation Methods and 
Guide to their Effects on Diffuse Water Pollution, Greenhouse Gas Emissions and Ammonia Emissions from Agriculture - User Guide. ADAS / Rothamsted Research, North Wyke, United Kingdom.

Rural Payments Agency. 2014. The Guide to Cross Compliance in England 2014, complete edition. Department of Environment, Food and Rural Affairs, London, United Kingdom.

Sharpley A, Daniel T, Edwards D. 1993. Phosphorus movement in the landscape. Journal of Production Agriculture 6(4): 492-500.

Sharpley A. 1995. Identifying sites vulnerable to phosphorus loss in agricultural runoff. Journal of Environmental Quality 24: 947-951.

Silgram M, Anthony S, Fawcett L, Stromqvist J. 2008. Evaluating catchment-scale models for diffuse pollution policy support: some results from the EUROHARP project, Environmental Science and Policy 11: 153-162.

Somma F. 2013. River Basin Network on Water Framework Directive and Agriculture: Practical Experiences and Knowledge Exchange in Support of the WFD Implementation (2010-2012). Publications Office of the European Union. Luxembourg. 